\title{
The Urban-Rural Education Inequality in 21st Century China
}

\author{
Xingyu $\mathrm{Wu}^{1 *}$ Haoran Zhang ${ }^{2}$, Yi $\mathrm{Hu}^{3}$
}

\author{
${ }^{1}$ Kent School, Kent, CT 06757, The United States \\ ${ }^{2}$ Nanjing Foreign Language School, Nanjing, Jiangsu 210008, China \\ ${ }^{3}$ Wuhan Britain China School, Wuhan, Hubei 430022, China \\ *Corresponding author.Email: xingyuwu2003@gmail.com,2679732075@qq.com, spencerhuyi@outlook.com
}

\begin{abstract}
China, as one of the fastest developing communist countries, has put enormous effort into narrowing the gap between urban-rural groups. Equality remains a hallmark of a communist country's ultimate success, and this paper focuses on the education reform policy's impact on and general trend of urban-rural education inequality in 21 st century China. For this research, we assessed 1626 people from the generation born in the 1980's and 1095 people from the generation born in the 1990's through the Mare transition model. We evaluated the policy's impact on and the trend of urban-rural education inequality through evaluation of the attainment of highest degrees by the aforementioned generations. The result showed that within two decades, the education gap between urban and rural students quickly narrows. Although there is still some level of urban-rural education inequality in high schools and colleges, most of it is diminished. This result of diminishing inequality in a more and more industrialized country also supports the Industrialization thesis, which states that as a country becomes more industrialized, education resources will be distributed more evenly based on personal abilities than on family backgrounds. This research demonstrates the efficacy of the Amendment of Compulsory Education Law of 2006 from the Chinese central government in reducing the gap between urban and rural groups in order to get a sufficient education.
\end{abstract}

Keywords: Education Inequality, Compulsory Education Law Policy, Urban-rural differences.

\section{INTRODUCTION}

At the dawn of the 21st century, China saw the emergence of numerous different subject-based prep institutions, which aimed to enhance the academic performance, test scores, of the students. These appearances of institutions did on some level improve a student's academic performance in terms of score, but it also added financial burdens to the family of the students as these institutions often required relatively high expenses to attend. More importantly, the prevalence of these institutions created pressure on parents, for if their kids did not attend these prep programs, their kids would stand on a disadvantaged ground from the start, something that a parent would not want to see. Such prevalence of institutions and burden coming along with it drew public attention to the question of whether education in China still provided a relatively level ground for both the poor and rich kids.

In 1986, the People's Republic of China passed the Compulsory Education Law of 1986. In this law, it said that every child possessing Chinese nationality regardless of their gender, ethnic, religious belief, financial circumstances, and many others should enjoy the right to and has to attend schools from grade one to nine. This law also forbade the schools from making profits off their students. Furthermore, in 2006, the People's republic of China passed the Amendment of Compulsory Education Law in the People's Congress. This amendment abolished the school-related fees, including tuition and sundries, to the families. This meant that parents of the students, especially ones from the rural areas, no longer needed to pay for the expenses of their children's schooling except their food. This might seem trivial to those of wealth, but it did alleviate much financial stress on the parents' parts in a poor neighborhood. Just a few years ahead of this amendment, in 1999, the Chinese central government passed a policy regarding college expansion. This policy increased the number of college enrollments from the original 963,000 students to 1.5 million students, which amounted to about $42 \%$ increase in college enrollments. All of these three acts - the Compulsory Education Law of 1986, the Amendment of Compulsory Education Law, 
and the College Expansion policy-seemingly reduced the education inequality in China. However, the answer remained to be ensured.

Li Chunling, a member of Chinese Academy of Social Sciences, discussed the urban-rural inequality in attaining the educational resources in her paper, The Changing Trend of Educational Inequality in China (1940-2010): Reexamining the urban-rural gap on educational opportunity [1]. In this paper, she examined such education inequality through the discussion of socioeconomic backgrounds and the policies passed in China in 1980s and 1990s, especially that of the Compulsory Education Law of 1986 and the College Expansion policy. She argued that Compulsory Education Law effectively reduced the gap between rural students and urban students by constructing new elementary schools and middle schools, thus saturating the market. However, the College Expansion policy didn't saturate the market for college students, so the education gap between rural and urban students in the terms of college opportunities was not effectively narrowed.

We also observed the relatively large number of voluntary dropouts of rural students from the middle schools, and three different factors contributed to this [2]. First, the enrollment rates to high schools for rural students were much lower than those of urban students. Due to the fact that possessing a high school degree did not necessarily bring an advantage over those of middle schools in the job markets, these rural students often considered dropping out and becoming a worker at age of sixteen[2]. Secondly, the exam-oriented education was mostly boring to rural students due to the lack of teachers and educational resources in that place[2]. Third, laws prohibiting the usage of child labour weren't strong reinforced, and the breachers of this law were not punished severely, which led to the appearance of underage workers .[2]

The definition of rural or urban regions still remains unanswered. In this paper, rural regions are non-urban areas, and urban areas include the suburbs of the cities, the cities and the towns. The characteristic of an urban area is that "there is a density of human structures such as houses, commercial buildings, roads, bridges, and railways [3]." Then, rural regions can be understood as places where there is not a density of human structures.

This paper will focus on whether education reform policy, especially the Amendment of Compulsory Education Law of 2006, effectively reduced the gap between rural and urban kids' access to educational resources. We are also interested in the subject of ruralurban education inequality because of the growing financial burdens to the parents and the appearances of early dropouts of the kids in the rural areas. In the consideration of education inequality, we will also examine the two major theses regarding the general trend of rural-urban education inequality in China: industrialization thesis, and social reproduction theory.

\section{LITERATURE REVIEW}

In the past section, two major yet conflicting theses were in place to be examined: industrialization thesis, and social reproduction theory, and this section will explain each one of them in detail.

Industrialization thesis meant that as a country became more industrialized, education resources would become more evenly distributed among different classes because with more developed industrialization, a country would demand more and more specialized jobs for different purposes in the industry [1]. These specialized jobs would require a highly stratified education system to serve the needs of the country [4]. This stratified education system will classify students more based on their own abilities over their families' backgrounds. Thus, the influence of parents as a socioeconomic factor for the access to education resources would serve a much lesser role in a more industrialized country.

Social reproduction theory, originated from Marxism, referred to the social oppression and the reproduction of social classes[1]. In the context of this paper, it referred to the theory that education served no longer as a tool to gain technical knowledge for a specific job as much as to re-reinforce the socioeconomic class already established in the country[5,6]. Despite the rapid industrialization of China and the open positions for emerging novel jobs, the privileged class would strive to take control of these new profitable jobs and pass them down to their later generations, which consequently pushed the underprivileged classes out of the reach of most ideal, profitable jobs [1]. In order to dominate profitable job markets, the privileged class usually took the control of high-level education resources, that of high schools, colleges and beyond.

\section{DATA AND METHODOLOGY}

The survey data used in this paper is from the 2017 Chinese General Social Survey [7] conducted by National Survey Research Center at Renmin University of China, NSRC (2017 CGSS). This is a large nationwide sample survey, which includes personal education experience and family background information. Based on the same sampling frame, this survey adopted the stratified multi-stage sampling method, and collected more than 7,200 households in 130 counties (cities and districts), 260 townships (towns and sub-districts) and 520 village housing committees covering 28 provinces, municipalities and regions in China [1]. We selected the generation born into the 1980s and the 1990s as target groups. The effective sample base for the generation born into the 1990s was 1097, and the effective sample base for the generation born into 1980s was 1626 . The data used in this paper derived from CGSS 2017. This data from CGSS 2017 could serve as the nationally representative survey data, for NSRC randomly selected $1 \%$ of the population to respond to the survey. A total of 2723 samples were obtained from the survey, and we analyzed these 2723 samples. Age groups were 
distinguished for comparative age analysis. People of different generations were exposed to different levels of educational resources, which reflected the educational inequality from the 1990 s to the 2000 s in China. Moreover, different age groups experienced different national policy changes and social and economic changes during their education experience, and the changes of educational inequality also reflected the influence of national policy, level of industrialization, educational expansion and class structure.

In our study, the total number of observations is 2721 , 1626 people from the generation born in the 1980s and 1095 people from the generation born in the 1990s. There are 1315 males, $48.4 \%$, and 1406 females, $51.6 \%$, in the

$$
\log \left(\frac{P_{i j}}{1-P_{i j}}\right)=\beta_{j 0}+\beta_{j} X_{i j}+\sum_{k} \lambda_{j k} V_{i j k}+\sum_{k} \theta_{j k} C_{i j k}+\sum_{c} \lambda_{j c} C X_{i j c}
$$

In this paper, logit Models of Educational Transitions designed by Mare are used to measure the trend of urban and rural education inequality in different years [7]. Dependent variable was the highest education qualification obtained by the students: graduate degree, undergraduate degree, high school degree, middle school degree, elementary school degree or none. The analysis of this paper focuses on the educational inequality between urban and rural areas and its changing trend for the people born from the 1980s to 1990s. Therefore, the independent variables of this study are gender, mother's residence at the birth of the respondents, Hukou for the 14-year-old respondent, respondent's Hukou at birth, parents' education level and parents' jobs.

Hukou referred to the record of respondents' residence in the Chinese central government, which directly determined the level of a person's exposure to the education resources or welfare within the counties. If a person's Hukou is Shanghai, he or she will be able to enjoy all privileges and education bonuses specific for those possessing the Shanghai Hukou.

At the same time, the sample was divided into two generations, people born in the 1980s and people born in the 1990s. In this way, the increasing or the decreasing gaps of urban-rural education opportunities can be accurately measured over the two generations.

The formula of this model is as follows:

*This formula is almost identical to that of multiple regression.

In this formula, $\mathrm{P}_{\mathrm{ij}}$ refers to the $\mathrm{i}$ 's percentage of getting into j's stage of education: illiterate, elementary schools, middle school, high schools, college and beyond, but the tables which appear later in this paper are indicating the graduating rates not the rate of just getting in. $X_{i j}$ determines if one is from a rural or urban region, and $\beta_{\mathrm{j}}$ is the coefficient of $X_{i j}$, which reflects on how much $X_{i j}$ influences one's education level. $V_{\mathrm{ijk}}$ is the control variables, including gender, parent's education level, parent's jobs, and so on, and $\Lambda_{\mathrm{jk}}$ is the coefficient of $\mathrm{V}_{\mathrm{ijk}}$. $\mathrm{C}_{\mathrm{ijk}}$ is the age group, the generations born in the $1990 \mathrm{~s}$ and the generations born in the $1980 \mathrm{~s}$, and $\theta_{\mathrm{jk}}$ is its coefficient. $\mathrm{CX}_{\mathrm{ije}}$ reflects the influence of birth, whether one is from a rural or urban region, in a specific generation, and $\lambda_{\mathrm{jc}}$ is its coefficient. sample of two generations. In the sample of generation born in the 1980s, there are 769 males, $47.3 \%$, and 857 females, $52.7 \%$. In the sample of generation born in the $1990 \mathrm{~s}$, there are 546 males, $49.9 \%$, and 549 females, $50.1 \%$. In the sample of generation born in the $1980 \mathrm{~s}$, there are 1136 people from the rural region, $69.9 \%$, and 490 people from the urban regions, $30.1 \%$. In the sample of generation born in the $1990 \mathrm{~s}$, there are 654 people from the rural region, $59.7 \%$, and 441 people from the urban regions, $40.3 \%$.

\subsection{Model}

\subsection{Variables:}

As shown in the above formula, the dependent variable of the admission model is the logarithm of the ratio between the students who have been admitted and those who have not been admitted in one of the five admission stages: primary school, middle school, high school, college and graduate programs.

Whether a person is from a rural or urban region was determined by his or her Hukou at the age of 14. If A's Hukou was registered at a rural location at age of 14 , it is assumed that A comes from a rural family; if B's Hukou was registered at a urban place at the age of 14, then it is assumed that B comes from an urban family; if C's hukou status is not determined at the age of 14, Hukou of C's father is used to determine whether $\mathrm{C}$ is from a rural or urban area. In the model, Hukou at the age of 14 is a dummy variable, with 1 for those born in urban families and 0 for those born in rural families.

For the simplicity of the research and analysis, we also categorized jobs of the parents into three major categories: white-collar workers; including party and government cadres, corporate managers, professional and technical personnel, business owners and general clerical staff; blue-collar workers; including farmers, service industry workers, and manufacturing workers; and the unemployed. In this model, the rural families were the reference group.

We also put the education level of students into six major categories: illiterate; elementary school; middle school; high school; including vocational high schools, technical secondary school, technical school and normal high school; college; including junior college, adult college and normal colleges; graduate and beyond. 


\section{ANALYSIS}

Table 1: Multiple Regression Outcome to the Highest Education Qualification of People born in the 1980s

\begin{tabular}{|c|c|c|c|c|c|}
\hline \multicolumn{3}{|c|}{ Number of observations } & \multicolumn{3}{|c|}{1,626} \\
\hline \multicolumn{3}{|c|}{ Adjusted R-squared } & \multicolumn{3}{|c|}{0.2695} \\
\hline Education & Coefficient & Standard error & $\mathrm{t}$ & $\mathrm{P}$ value & $\begin{array}{c}95 \% \\
\text { confidence } \\
\text { interval }\end{array}$ \\
\hline Gender & -0.3101049 & 0.14857 & -2.09 & 0.037 & $\begin{array}{l}-0.6015163 \mid \\
-0.0186936\end{array}$ \\
\hline Mother's Residence & 0.2265435 & 0.126735 & 1.79 & 0.074 & $\begin{array}{c}-0.0220385 \\
0.4751255\end{array}$ \\
\hline $\begin{array}{l}\text { Hukou at the age of } \\
14\end{array}$ & 0.7031306 & 0.1305918 & 5.38 & 0.000 & $\begin{array}{c}0.4469837 \mid \\
0.9592774 \\
\end{array}$ \\
\hline $\begin{array}{c}\text { Father's Education } \\
\text { Level }\end{array}$ & -0.0064961 & 0.0062006 & -1.05 & 0.295 & $\begin{array}{c}-0.0186582 \mid \\
0.0056659\end{array}$ \\
\hline Father's Job & -1.074928 & 0.1588765 & -6.77 & 0.000 & $\begin{array}{r}-1.386553 \mid \\
-0.7633023\end{array}$ \\
\hline $\begin{array}{c}\text { Mother's Education } \\
\text { Level }\end{array}$ & 0.0104297 & 0.0072593 & 1.44 & 0.151 & $\begin{array}{c}-0.0038089 \\
0.0246682 \\
\end{array}$ \\
\hline Mother's Job & -0.3893338 & 0.1197733 & -3.25 & 0.001 & $\begin{array}{l}-0.6242611 \\
-0.1544066\end{array}$ \\
\hline Hukou at Birth & -0.2481368 & 0.1662054 & -1.49 & 0.136 & $\begin{array}{c}-0.5741374 \mid \\
0.0778638\end{array}$ \\
\hline Constant & 8.262822 & 0.3849059 & 21.47 & 0.000 & $\begin{array}{l}7.507855 \\
9.017789 \\
\end{array}$ \\
\hline
\end{tabular}

Table 2: Multiple Regression Outcome to the Highest Education Qualification of People born in the 1990s

\begin{tabular}{|c|c|c|c|c|c|}
\hline \multicolumn{3}{|c|}{ Number of observations } & \multicolumn{3}{|c|}{1,097} \\
\hline \multicolumn{3}{|c|}{ Adjusted R-squared } & \multicolumn{3}{|c|}{0.1344} \\
\hline education & Coefficient & $\begin{array}{l}\text { Standard } \\
\text { error }\end{array}$ & $\mathrm{t}$ & $P$ value & $\begin{array}{l}95 \% \text { confidence } \\
\text { interval }\end{array}$ \\
\hline Gender & 0.3244661 & 0.1834777 & 1.77 & 0.077 & $\begin{array}{c}-0.0355437 \mid \\
0.6844758\end{array}$ \\
\hline $\begin{array}{c}\text { Mother's } \\
\text { Residence } \\
\end{array}$ & 0.2331912 & 0.189695 & 1.23 & 0.219 & $\begin{array}{c}-0.1390179 \\
0.6054002 \\
\end{array}$ \\
\hline $\begin{array}{c}\text { Hukou at the Age } \\
\text { of } 14\end{array}$ & 0.5326924 & 0.1894654 & 2.81 & 0.005 & $\begin{array}{l}0.1609338 \mid \\
0.9044509 \\
\end{array}$ \\
\hline $\begin{array}{c}\text { Father's Education } \\
\text { Level }\end{array}$ & -0.0081542 & 0.0080828 & -1.01 & 0.313 & $\begin{array}{c}-0.0240138 \mid \\
0.0077054\end{array}$ \\
\hline Father's Job & -0.613478 & 0.19466 & -3.15 & 0.002 & $\begin{array}{c}-0.9954291 \mid \\
-0.231527\end{array}$ \\
\hline $\begin{array}{c}\text { Mother's } \\
\text { Education Level }\end{array}$ & 0.0185655 & 0.0112267 & 1.65 & 0.098 & $\begin{array}{l}-0.003463 \\
0.0405939\end{array}$ \\
\hline Mother's Job & -0.5157384 & 0.1442648 & -3.57 & 0.000 & $\begin{array}{l}-0.7988069 \mid \\
-0.2326699 \\
\end{array}$ \\
\hline Constant & 8.003911 & 0.4889107 & 16.37 & 0.000 & $\begin{array}{l}7.044598 \mid \\
8.963225\end{array}$ \\
\hline
\end{tabular}

Table 1 demonstrates the results of a multiple regression. This regression studies the relations of eight variables; gender, mother's residence, Hukou at the age of 14, father's education level, father's job, mother's education level, mother's job, Hukou at birth; to the education level of a person born in the 1980s.

Table 2 demonstrates the results of another multiple regression. This regression studies the relations of seven variables; gender, mother's residence, Hukou at the age of 14, father's education level, father's job, mother's education level, mother's job; to the education level of a person born in the 1990s.

Table 1 included 1626 observations of people born into the 1980s, and Table 2 included 1,097 observations of people born into the 1990s. Both of the regressions are analyzing the relation of gender, mother's residence, 
Hukou at the age of 14, parents' education levels, and parents' jobs to the highest education qualification received by a person. Everything except father's education level contributes to the high degrees received to some degree. An explanation of father's education level being irrelevant and insignificant may be that fathers usually take the financial responsibility of the family but do not involve themselves in the chores within the households. Both of the P values of father's job being below 0.01 are a strong proof to the previous statement. $\mathrm{P}$ values of mother's education level, 0.151 for the generation born in the 1980s and 0.098 for the generation born in the 1990s, are much lower than those of the fathers', but they are both above 0.05 meaning it can't be significant enough to be a major factor to the attainment of degrees. It can be a minor one.

The factor of gender for people born in the 1980s has a $\mathrm{p}$ value below 0.05 and a negative coefficient. This indicates that being a female born in the 1980s has a disadvantage in gaining high education degrees. However, for a person born in the 1990s, the $\mathrm{p}$ value of gender increases and is between 0.1 and 0.05 (90\% to $95 \%$ confidence interval) and has a positive coefficient. This indicates the rise of female status in the sense of attaining higher degrees and may also imply their rise in the social status in China in general.

Mother's residence at the birth of her child becomes much less significant over the decade from 0.074 to 0.219 , to a fact unknown, and the $\mathrm{P}$ value of Hukou at the age of 14, 0.00 , ensures us to use it as the determinant of whether a person is from rural or urban regions instead of Hukou at birth. $\mathrm{P}$ values of Mother's job, 0.01 for the generation born in the 1980s and 0.00 for the generation born in the 1990s, and its negative coefficient indicate that mother being unemployed and a housewife will contribute positively to the education level of her children.

Table 3: The Highest Education Qualification obtained by the Rural Students born in the 1980s

\begin{tabular}{|c|c|c|c|}
\hline & Number & Percentage & Cumulative percentage \\
\hline No education experience & 20 & 1.76 & 1.76 \\
\hline Elementary school & 128 & 11.27 & 13.03 \\
\hline Middle school & 460 & 40.49 & 53.52 \\
\hline High school & 256 & 22.54 & 76.06 \\
\hline College & 246 & 21.65 & 97.71 \\
\hline Graduate and beyond & 26 & 2.29 & 100.00 \\
\hline total & 1,136 & 100.00 & \\
\hline
\end{tabular}

Table 4: The Urban Students born in the 1980's

\begin{tabular}{|c|c|c|c|}
\hline & Number & Percentage & Cumulative percentage \\
\hline No education experience & 10 & 2.04 & 2.04 \\
\hline Elementary school & 3 & 0.61 & 2.65 \\
\hline Middle school & 38 & 7.76 & 10.41 \\
\hline High school & 86 & 17.55 & 27.96 \\
\hline College & 306 & 62.45 & 90.41 \\
\hline Graduate and beyond & 47 & 9.59 & 100.00 \\
\hline total & 490 & 100.00 & \\
\hline
\end{tabular}

Table 3 indicates the percentage of different education levels obtained by the rural students born in the 1980s. For example, the table shows that there are 20 rural students, $1.76 \%$ overall, who did not attend schools at all in the 1980s.

Table 4 indicates the percentage of different education levels obtained by the urban students born in the 1980s. For example, the table shows that there are 10 urban students, $2.04 \%$ overall, who did not attend schools at all in the 1980s.

Table 3 demonstrates the percentage of the highest education qualification attained by the rural students born in the 1980s, and Table 4 demonstrates the percentage of the highest education qualification degrees attained by the urban students born in the 1980s. The major ruralurban percentage differences between the students from their respective places in the sense of attaining the middle school degree and below are shocking. $53.52 \%$ of the rural students had a degree of middle schools or below in contrast to the $10.41 \%$ of the urban students attaining a degree of middle schools or below. Simple subtraction indicates a $43.11 \%$ difference between those of rural and urban students, a huge gap that couldn't be overlooked. However, the percentage difference of attaining high 
school degrees between rural and urban students is deceiving, for we notice that this table is not the enrollment rate but the highest education qualification that each received. $22.54 \%$ of high school degrees for the rural students is larger than $17.55 \%$ of those for the urban students. This is due to the fact that a significant number of more urban students go to colleges than rural students.
$72.04 \%$ of the urban students continued to pursue their career in education after high school while only $23.94 \%$ of rural students did. This was a $48.1 \%$ difference. To read this graph, it was important to realize that the cumulative percentage told a much better and detailed story than the simple percentage of each degree.

Table 5: The Rural Students born in the 1990s

\begin{tabular}{|c|c|c|c|}
\hline & Observations & Percentage & Cumulative percentage \\
\hline No education experience & 6 & 0.92 & 0.92 \\
\hline Elementary school & 21 & 3.21 & 4.13 \\
\hline Middle school & 146 & 22.32 & 26.45 \\
\hline High school & 200 & 30.58 & 57.03 \\
\hline College & 273 & 41.74 & 98.78 \\
\hline Graduate and beyond & 8 & 1.22 & 100.00 \\
\hline total & 654 & 100.00 & \\
\hline
\end{tabular}

Table 6: Urban Students born in 1990's

\begin{tabular}{|c|c|c|c|}
\hline & Observations & Percentage & Cumulative percentage \\
\hline No education experience & 6 & 1.36 & 1.36 \\
\hline Elementary school & 0 & 0 & 1.36 \\
\hline Middle school & 21 & 4.76 & 6.12 \\
\hline High school & 104 & 23.58 & 29.71 \\
\hline College & 284 & 64.40 & 94.10 \\
\hline Graduate and beyond & 26 & 5.90 & 100.00 \\
\hline total & 441 & 100.00 & \\
\hline
\end{tabular}

Table 5 indicates the percentage of different education levels obtained by the rural students born in the 1990s. For example, the table shows that there are 6 rural students born in the $1990 \mathrm{~s}, 0.92 \%$ overall, who did not attend schools at all.

Table 6 indicates the percentage of different education levels obtained by the urban students born in the 1990s. For example, the table shows that there are 6 urban students born in the $1990 \mathrm{~s}, 1.36 \%$ overall, who did not attend schools at all.

Table 5 demonstrates the percentage of the highest education qualification attained by the rural students born in the 1990s, and Table 6 demonstrates the percentage of the highest education qualification attained by the urban students in the same generation. The urban-rural percentage difference between students in the sense of attaining the middle school degrees and below is largely reduced. $26.45 \%$ of the rural students had a degree of middle schools or below in contrast to the $6.12 \%$ of the urban students attaining a degree of middle schools or below. Another simple subtraction shows 20.32\% difference between those of rural and urban students, a $22.79 \%$ decrease within the urban-rural gap on attaining middle school degrees or below. The significant reduction can partly be explained by the implementation of the Amendment of Compulsory Education Law of 2006. $70.3 \%$ of the urban students continued to pursue education after high school when $42.96 \%$ of the rural students also did so. The $27.34 \%$ gap was much smaller than $48.1 \%$ in the previous decade. The fast-increasing GDP per capita of China and improved welfare systems may contribute to this narrowing gap, for more and more rural students have the opportunities to go to colleges for further study than before, which will be elaborately illustrated later in the article.

In this paragraph, we discuss the increasing level of education experience in the rural areas over the decade. The percentage of rural students with degrees of middle school or below dropped from $53.52 \%$ for the generation born in the 1980 s to $26.45 \%$ for the generation born in the 1990s, a $27.07 \%$ decrease. The Amendment of Compulsory Education Law of 2006 is seen as a major cause of this decrease. Also, the percentage of rural students pursuing education experience beyond high schools increased from $23.94 \%$ for the generation born in 
the 1980 s to $42.96 \%$ for the generation born in the $1990 \mathrm{~s}$, an $19.02 \%$ increase.

Similarly, there is also a relatively increasing level of education experience in the urban areas over the decade. The percentage of urban students with degrees of middle school or below dropped from $10.41 \%$ for the generation born in the 1980 s to $6.12 \%$ for the generation born in the 1990 s, an $4.29 \%$ decrease. The number may look small in comparison to the change of the rural students' education level, but this $4.29 \%$ number meant that over the decade, the amendment effectively reduced about $50 \%$ of the original urban body of middle school degrees and below. Surprisingly, the percentage of urban students pursuing education experience beyond high schools dropped from $72.04 \%$ for the generation born in the 1980 s to $70.30 \%$ for the generation born in the 1990 s, an $1.74 \%$ decrease. The shocking $19.02 \%$ increase of rural students pursuing education experience beyond high schools over the decade may contribute to this minor decrease, for there was a relatively fixed number of highlevel education resources open to students, and if there were more competitors, it would be harder to get into a college.

\subsection{The Amendment of Compulsory Education Law of 2006}

The Amendment of Compulsory Education Law aimed to alleviate the financial burdens of rural students by abolishing most of the school-related fees in the elementary schools and middle schools. The oldest student to be affected by this law when it is implemented will be fifteen years old. Thus, a 15-year-old student in 2006 will be born in 1991. The year, 1991, will be the event day. We will investigate the percentage of the highest education qualifications received nine years prior to the event year, from 1982 to 1990 , and nine years since the event year, from 1991 to 1999.

In this research, there are 996 students from the rural regions, $68.2 \%$, and 465 students from the urban regions, $31.8 \%$. for the generation born from 1982 to 1990 (46.1\% male and $53.9 \%$ female). There are also 561 students from the rural regions, $59.4 \%$, and 383 students from the urban regions, $40.6 \%$, for the generation born from 1991 to 1999 (50.1\% male and $49.9 \%$ female).

Table 7: The Rural Students born from 1982-1990

\begin{tabular}{|c|c|c|c|}
\hline & observations & percentage & cumulative percentage \\
\hline illiterate & 12 & 1.20 & 1.20 \\
\hline Elementary school & 103 & 10.34 & 11.54 \\
\hline Middle school & 391 & 39.26 & 50.8 \\
\hline High school & 230 & 23.09 & 73.89 \\
\hline College & 236 & 23.69 & 97.58 \\
\hline Graduate and beyond & 24 & 2.41 & 100.00 \\
\hline total & 996 & 100 & \\
\hline
\end{tabular}

Table 8: The Urban Students born from 1982-1990

\begin{tabular}{|c|c|c|c|}
\hline & observations & percentage & cumulative percentage \\
\hline Illiterate & 11 & 2.37 & 2.37 \\
\hline Elementary school & 2 & 0.43 & 2.8 \\
\hline Middle school & 33 & 7.10 & 9.9 \\
\hline High school & 74 & 15.91 & 25.81 \\
\hline College & 297 & 63.87 & 89.68 \\
\hline Graduate and beyond & 48 & 10.32 & 100.00 \\
\hline total & 465 & 100 & \\
\hline
\end{tabular}

Table 7 indicates the percentage of different education levels obtained by the rural students born from 1982 to 1990 . For example, the table shows that there are 12 rural students born from 1982 to 1990, $1.20 \%$ overall, who did not attend schools at all.
Table 8 indicates the percentage of different education levels obtained by the urban students born from 1982 to 1990 . For example, the table shows that there are 11 rural students born from 1982 to 1990, $2.37 \%$ overall, who did not attend schools at all. 
Table 7 claims the percentage of the highest education qualification attained by the rural students born from 1982 to 1990 , and the Table 8 demonstrates the percentage of the highest education qualification that are attained by the urban students born from 1982 to 1990 . There is a major rural-urban percentage difference between the pupils from their respective places in the sense of attaining the middle school degrees and below: $50.8 \%$ of the rural students achieve to the middle school degree level or below in contrast to the $9.9 \%$ of the urban candidates gaining a degree of middle schools or even below. After the simple subtraction, there is a $40.9 \%$ gap between the education level of the rural and urban pupils. Table 7 and Table 8 also demonstrate that $23.09 \%$ of rural students obtain a high school degree while only $15.91 \%$ of the urban students do because much more urban students go further into the college education than rural students. There are $74.19 \%$ of the urban students who continued to study further in the college or achieved beyond, while only $26.1 \%$ rural students did, a $48.19 \%$ difference.

Table 9: The Rural Students born from 1991-1999

\begin{tabular}{|c|c|c|c|}
\hline & observations & percentage & cumulative percentage \\
\hline illiterate & 5 & 0.89 & 0.89 \\
\hline Elementary school & 15 & 2.67 & 3.57 \\
\hline Middle school & 118 & 21.03 & 24.60 \\
\hline High school & 172 & 30.66 & 55.26 \\
\hline College & 244 & 43.49 & 98.75 \\
\hline Graduate and beyond & 7 & 1.25 & 100.00 \\
\hline total & 561 & 100 & \\
\hline
\end{tabular}

Table 10: The Urban Students born from 1991-1999

\begin{tabular}{|c|c|c|c|}
\hline & observations & percentage & cumulative percentage \\
\hline illiterate & 5 & 1.31 & 1.31 \\
\hline Elementary school & 0 & 0 & 1.31 \\
\hline Middle school & 21 & 5.48 & 6.79 \\
\hline High school & 92 & 24.02 & 30.81 \\
\hline College & 244 & 63.71 & 94.52 \\
\hline Graduate and beyond & 21 & 5.48 & 100.00 \\
\hline total & 383 & 100 & \\
\hline
\end{tabular}

Table 9 indicates the percentage of different education levels obtained by the rural students born from 1991 to 1999 . For example, the table shows that there are 5 rural students born from 1991 to $1999,0.89 \%$ overall, who did not attend schools at all.

Table10 indicates the percentage of different education levels obtained by the urban students born from 1991 to 1999. For example, the table shows that there are 5 urban students born from 1991 to 1999 , $1.31 \%$ overall, who did not attend schools at all.

Table 9 describes the percentage of the highest education qualification attained by the rural students born from 1991 to 1999 and Table 10 demonstrates the percentage of the highest education qualification of urban students born from 1991 to 1999. Over the implementation of the Amendment of Compulsory Education by Chinese central government, only $24.60 \%$ of the rural students achieved the middle school degree level or below in contrast to the $6.79 \%$ of the urban students gaining a degree of middle schools or even below, a $17.81 \%$ difference gap. The gap shrank $23.09 \%$ over the nine years after the implementation of the law. There are $69.19 \%$ of the urban students who continue to study further in the college education or achieve beyond that, while $44.74 \%$ rural students do, a $24.45 \%$ difference. However, the difference really shrank about $23.74 \%$ in comparison to the $48.19 \%$ difference of nine years prior to the amendment. It is partly due to the amendment but also due to the improving quality of education resources, including better teachers, better school infrastructure, and so on.

By comparing Table 7 and Table 9, it was obvious that the low-education group of rural regions, those of whom only finish middle schools or below, decreased by more than a half, from $50.8 \%$ to $24.6 \%$ over the implementation of the amendment. Also, the number of rural college students or those with graduate degrees 
increased about 1.7 times over nine years after the amendment, from $26.1 \%$ to $44.74 \%$.

Also, because of the nine-year compulsory education, the percentage of urban students obtaining middle school degrees and below dropped from $9.9 \%$ to $6.79 \%$, but those in urban regions obtaining college degrees and beyond decreased from $74.19 \%$ to $69.19 \%$ over the span of 18 years. As mentioned in the previous section, the appearance of many more rural competitors in entering colleges and beyond takes the responsibility for this percentage decrease of college degrees and beyond in the urban areas.

\section{CONCLUSION}

The dawn of 21 st century China sees the narrowing education gap between rural and urban students. The low education group of rural regions, those attaining middle school degrees and below, is reduced by more than a half. The difference between urban and rural students obtaining college degrees and beyond also narrowed in a surprising way, in which the urban college student body actually dropped in percentage.

All of this narrowing gap and differences seem to support the industrialization thesis. The diminishing education inequality between rural and urban students also reflect on the mobility of socioeconomic classes because students of higher education degrees possess an advantage over those of lower degrees[8]. Despite the existing problem about the difficulty of college students finding well-paid jobs, numerous college students will adequately satisfy many different needs in a highly industrialized country, like China. According to the data analysis, China achieved a more equal and fair education system through its education reform policies and industrialization in the 21 st century although there was not an obvious decrease in relation of families' backgrounds to one's education level. This may apply to India and North Korea, which are also developing rapidly in the process of industrialization.

China also sees one of the biggest waves of their students going abroad to developed countries for education in the 2010s. This wave of international students might prove counterproductive to the Chinese central government's efforts to narrow the education inequality, for most of the time, only students of wealthy backgrounds can study abroad. Studying the influx and outflow of international students could further improve understanding of narrowing urban-rural inequality in China.

Around the date when this paper was written, July 2021, the Chinese central government passed an education reform policy which aims to alleviate the burdens of students by reducing the huge amount of schoolwork and the huge expense paid by the parents to the prep institutions [9]. It states that the central government will no longer allow any newer emergencies of subject-based prep institutions, and the existing institutions will become non-profitable. The impact of this policy on urban-rural education inequality remains to be investigated [10].

\section{REFERENCES}

[1] Li, C. (2014). The Changing Trend of Educational Inequality in China (1940-2010): Reexamining the urban-rural gap on educational opportunity. CNKI.

[2] Yuan, H., \& Liu, D. (2019). Investigation into Voluntary Dropouts of Rural Students. CNKI.

[3] Urban Area. (2021). Resource Library.

[4]Treiman, D. J. (1970). Industrialization and Social Stratification. Sociological Inquiry.

[5] Collins, R. (1971). Functional and Conflict Theories of Educational Stratification. JSTOR.

[6] Mare, R. D. (1981). Change and Stability in Educational Stratification. American Sociological Review 46.

[7] Chinese General Social Survey. (2017). http://cnsda.ruc.edu.cn/index.php?r=projects/view \&id=94525591

[8] Peng, J., \& Zhao, X. (2021). The Effect of Educational Policy on Intergenerational Education Mobility in Rural Areas. CNKI.

[9] Li, S. (2021) Multiple Public Education Companies Responding to the Education Reform Policy. CNKI.

[10] Pang, X. (2019). Study on the Urban-rural Differences Between Intergenerational Transmission of Education in China-The analysis based on the data of Chinese General Social Survey (CGSS). CNKI. 